\title{
A Framework for ERP Post-Implementation Amendments: A Literature Analysis
}

\author{
Taiwo Oseni \\ Federation University Australia \\ t.oseni@federation.edu.au
}

\section{Susan Foster}

Monash University

\author{
Mahbubur Rahim \\ Monash University
}

\section{Stephen Patrick Smith \\ Monash University}

\section{Abstract}

Post-implementation amendments to ERP systems (ERP-PIA) are of importance for advancing ERP research, but more importantly essential if ERP systems are to be used as a strategic and competitive business tool. For ease of clarity, we have adopted the term "amendments" to encompass the main forms of post implementation activities: maintenance, enhancements and upgrades. The term "amendments" is used to counteract one of the major findings from this research - the inconsistency of terms used by many authors to explain post implementation activities. This paper presents a review of the ERP post-implementation amendment literature in order to provide answers to two specific questions: first, what is the current state of research in the field of ERP-PIA; and second, what are the future research directions that need to be explored in the field of ERP-PIA. From the review, we develop a framework to identify: (a) major themes concerning ERP post-implementation amendments, (b) inherent gaps in the post-implementation amendments literature, and (c) specific areas that require further research attention influencing the uptake of amendments. Suggestions on empirical evaluation of research directions and their relevance in the extension of existing literature is presented.

Keywords: Post-implementation modifications; ERP; maintenance; enhancements; upgrades

\section{Introduction}

Companies spend millions of dollars in maintenance and support activities involved with ERP post-implementation. A Gartner study (2003) identified that, on average, 11\% of a company's IT budget allocation is spent on application support and maintenance. To put this figure into context, the authors state that, as a rough estimate, "Organisations should plan to spend 40\% to $60 \%$ of the initial implementation costs to maintain their ERP system for every year that it is in full production". This advice is still relevant today given that maintenance and upgrade costs are ever present in the yearly ERP budget. Client companies of some of the larger ERP vendors, such as SAP and Oracle, can be charged hundreds of thousands if not millions of dollars in maintenance per year (Olsaker, 2010). For example, a CFO research study involving 157 senior finance executives (CFO Research Services, 2009) confirms that the ongoing costs of maintaining, modifying, and updating an ERP system is substantial, even for mid-sized organisations. In some cases, such cost run to about $17 \%$ to $22 \%$ of the initial implementation cost (Olsaker, 2010).

Unfortunately, limited information is available to assist organisations in making informed decisions concerning the management of this cost after implementation. As a result, some organisations are finding that post-implementation amendments often do not justify the fees paid to vendors. For instance, Dana, an $\$ 8$ billion dollar auto parts supplier, was reported to have stopped making maintenance payments to its ERP vendor and scaled back on ERP 
maintenance projects in order to cut costs (Nash, 2007). This type of behaviour is understandable; although post implementation amendments are required to exploit ERP capabilities effectively, amendments are costly and time consuming to perform and may not produce any measurable benefit unless carefully managed. (Peng \& Nunes, 2010). Having a better understanding of post-implementation amendments is certainly a first step to ensuring successful uptake of amendments.

In the academic and practitioner literature, the topic of ERP post-implementation issues encompassing ongoing requirements, user support, maintenance and upgrades have received scant attention in comparison with adoption and implementation issues (Law, Chen, \& Wu, 2010). This is a considerable failing since ERP implementation projects are almost invariably followed by maintenance, enhancement, and upgrade projects. Post-implementation amendments are relevant and deserve adequate research attention, especially since future benefits obtainable from ERP systems are moderated by post-implementation changes (Cao, Nicolaou, \& Bhattacharya, 2013).

This paper presents a review of the ERP-PIA literature, a framework to analyse and synthesise prior research on post-implementation amendments, identifies the gaps in the literature and presents the major themes concerning ERP post-implementation amendments. The outcomes offer a resource for researchers who may be interested in issues affecting ERP systems postimplementation thus encouraging the undertaking of more rigorous research to further examine post-implementation issues. For the ERP practitioner community, a review of the post-implementation amendments' literature provides an in-depth knowledge of the critical issues surrounding such amendments.

\section{A Background to ERP post-implementation Amendments}

An Enterprise Resource Planning (ERP) system is a type of packaged application software that is capable of fully integrating and automating business processes across functional areas. In addition, ERP systems are capable of centralising operational information so that it can be shared by an organisation's key functional systems, and to facilitate rapid decision making, cost reductions, and greater managerial control (Davenport, Harris, \& Cantrell, 2004; Galy \& Sauceda, 2014; Klans, Rosemann, \& Gable, 2000). These systems further offer provision for mobility with anywhere anytime access to an organisations' resources as well as connectivity to more advanced enterprise systems such as: supply chain management (SCM), customer relationship management (CRM), advanced planning and optimisation (APO), and business intelligence (BI) (Motiwalla \& Thompson, 2009).

After the initial implementation of ERP systems, companies are continually required to make post-implementation amendments. Such amendments include maintenance, enhancement, and upgrade activities which are referred to in literature by a variety of terms such as: maintenance activities, maintenance practices, enhancements, changes, amendments revisions, and upgrades; making it difficult to disentangle the meanings with any clarity. To address the issue of inconsistent terminology, and reduce the terms to a common denominator we use the term amendments. In the following sections, we present the current state of research in the field of ERP-PIA.

\section{A Review of the ERP-PIA Literature}

In this study, we have followed a three-step approach for reviewing the ERP-PIA literature: Step 1 - identification of articles discussing amendments; Step 2 - development of a framework to guide the discussion on amendments; and Step 3 - discussion on amendments. This is presented in Figure 1. 


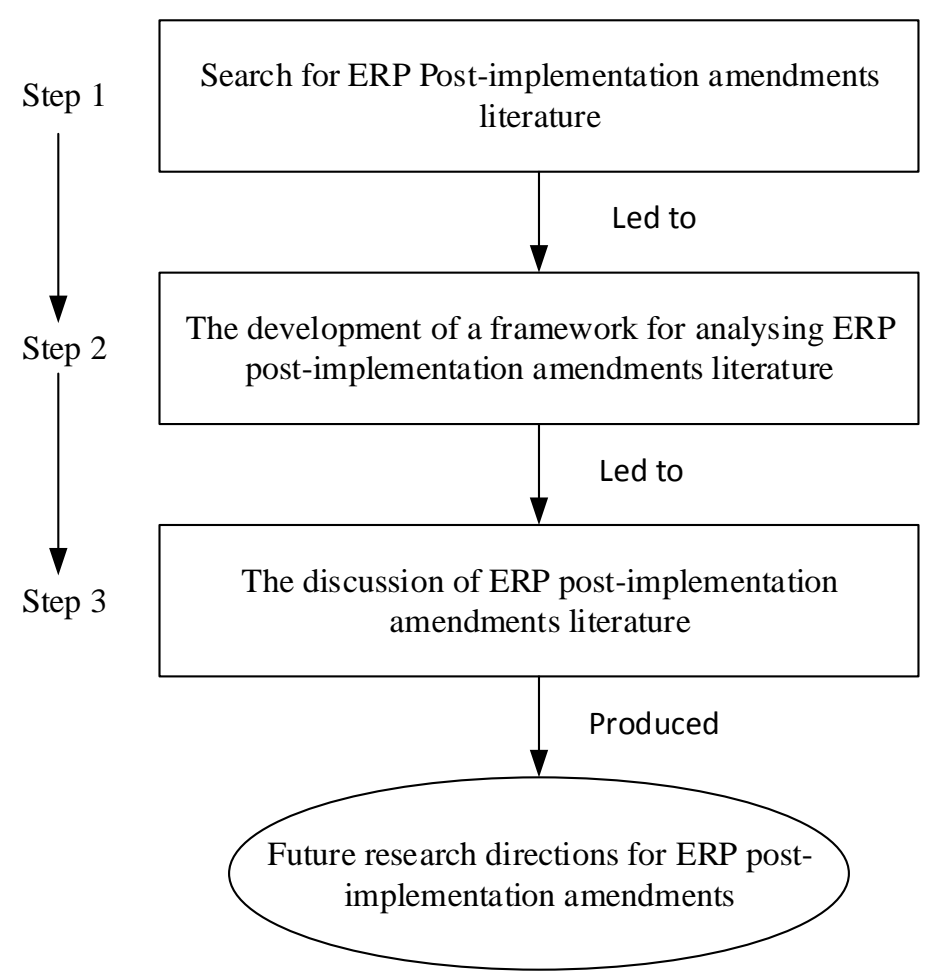

Figure 1. Three-step approach to reviewing the ERP-PIA literature

Step 1 includes a wide search for publications documenting one or more forms of amendments. Following on the realisation, from Step 1, that as yet no review has been conducted for ERP post-implementation amendments, we thus developed a framework for reviewing and analysing the literature: the framework is referred to as the ERP-PIA framework. Frameworks have been used in the wider ERP literature for clarifying and presenting a holistic view of the ERP literature. The absence of such a framework to assess ERP-PIA can restrict the development of a richer understanding of ERP-PIA. These three steps eventually culminated in the identification of directions for further research on ERP-PIA.

\subsection{Step 1: A Search for ERP-PIA Literature}

To develop an overview of academic activity relating to ERP post-implementation amendments, top level IS journals were scanned for the period 2000 - 2016. The timeframe was chosen because ERP systems became predominant in the late 1990 and early 2000 as a result of the Y2K phenomenon. The search was made through the use of such key words as ERP post-implementation, ERP amendments, ERP maintenance, ERP upgrades, ERP enhancement, and ERP post-implementation changes. In particular, only articles with either 'ERP', 'enterprise resource planning', or 'enterprise systems' together with either 'maintenance', 'upgrade', 'enhancement', 'amendments' or 'post-implementation changes' in their titles were selected These key words were chosen as they represent some of the terms used in the prior ERP literature review articles to indicate those activities that concern ERP systems after implementation. The key words were also informed by the definition of ERP postimplementation amendments as inclusive of all forms of maintenance, enhancements and upgrades (Information Resources Management Association, 2011).

The criteria for choosing articles discussing ERP post-implementation amendments are as follows: first, the article must have been published in a peer-review journal; second, 31 October 2016 was selected as the cut-off date; hence, the articles must have been published before the cut-off date; and thirdly, only articles having one or more of the key words (mentioned in the previous paragraph) in their titles were selected. The process of selection included four rounds of searches that identified a total of 26 articles on ERP post-implementation amendments. First round of search was restricted to those journals listed on the IS journals ranked by the 
Australian Council of Professors and Heads of Information Systems (ACPHIS) in 2013 (ACPHIS, 2013). A complete list of the 2013 ACPHIS journal ranking can be accessed via the following link: http://www.acphis.org.au/index.php/is-journal-ranking. This list comprises 181 journals, from which a total of 19 articles discussing ERP post-implementation amendments were identified. Second round of search was done using Google scholar and Scopus search engines, from which additional six articles were identified from journals that are not in the ACPHIS list. Third round of search was done by reviewing the citations for the articles identified in the first and second rounds as recommended by Webster and Watson (2002). One article, published in one of the ACPHIS journals, was identified through this round. We had previously missed this article in the first round of search as its title and abstract does not include one of the main key words. Instead, key words such as 'ERP', 'enterprise resource planning' and 'enterprise systems' had been replaced with 'packaged application software'. The fourth round of search, again as recommended by Webster and Watson (2002), was done to identify articles citing the key articles identified in the previous rounds. This search however identified no relevant journal article that could be included in our review.

Altogether, the 26 articles were identified by the lead researcher. However, each member of our research team individually read the title, key words, abstract, and introduction of each article. By carefully reading the details provided in the abstract and introduction, each of the 26 articles were considered by the team to be appropriate for inclusion in our analysis.

The ACPHIS list contained $13 \mathrm{~A}^{*}$ journals, 39 A journals, 50 B journals, and $79 \mathrm{C}$ journals. Out of about 86 ERP articles published across all $13 \mathrm{~A}^{*}$ journals, only four articles were found discussing ERP post-implementation amendments. In order to indicate this, a list of journals, in which articles on ERP post-implementation amendments were published, along with the number of articles appearing in each journal is presented in Table 1.

\begin{tabular}{|c|c|c|c|c|}
\hline $\begin{array}{l}\text { Level of } \\
\text { Journal }\end{array}$ & Journal Name & $\begin{array}{l}\text { No. of } \\
\text { ERP-PIA } \\
\text { articles }\end{array}$ & $\begin{array}{c}\text { Year of } \\
\text { Publication }\end{array}$ & $\begin{array}{c}\text { Total } \\
\text { no. of } \\
\text { articles }\end{array}$ \\
\hline \multirow{3}{*}{$A^{*}$} & European Journal of Information Systems & 1 & 2007 & \multirow{7}{*}{11} \\
\hline & Information and Management & 1 & 2011 & \\
\hline & Journal of Information Technology & 2 & $2010 ; 2011$ & \\
\hline \multirow{4}{*}{ A } & Communications of the ACM & 2 & $2000 ; 2006$ & \\
\hline & Enterprise Information Systems & 2 & $2007 ; 2010$ & \\
\hline & Journal of Computer Information Systems & 2 & $2006 ; 2007$ & \\
\hline & Journal of Information Systems & 1 & 2013 & \\
\hline $\mathrm{B}$ & Journal of Systems and Software & 2 & $2002 ; 2010$ & \multirow{4}{*}{9} \\
\hline \multirow{3}{*}{$\mathrm{C}$} & Expert Systems with Applications & 1 & 2001 & \\
\hline & $\begin{array}{l}\text { Journal of Software Maintenance and } \\
\text { Evolution }\end{array}$ & 5 & 2001 & \\
\hline & $\begin{array}{l}\text { Journal of Cases on Information } \\
\text { Technology }\end{array}$ & 1 & 2006 & \\
\hline \multirow{6}{*}{$\begin{array}{l}\text { Non- } \\
\text { ACPHIS } \\
\text { IS } \\
\text { journals }\end{array}$} & Journal of Accounting Information Systems & 1 & 2006 & \multirow{6}{*}{6} \\
\hline & Computers in Industry & 1 & 2010 & \\
\hline & IEEE transactions on Software Engineering & 1 & 2012 & \\
\hline & Computer Standard and Interfaces & 1 & 2014 & \\
\hline & Industrial Management and Data Systems & 1 & 2009 & \\
\hline & Global Journal of Human Social Science & 1 & 2013 & \\
\hline
\end{tabular}

Table 1: Literature search for ERP post-implementation amendments

From the table, it can be observed that 42\% (11) of ERP-PIA articles were published in leading $\mathrm{A}^{*}$ and A journals; while 35\% (9) were published in B and C journals, and the remaining $23 \%$ (6) in non-ACPHIS journals. This shows that ERP post-implementation amendments are considered relevant, even for leading IS journals. 
A key observation from Table 2 reflects the decline in the number of published articles that focus on ERP-PIA. This is personified in Fig 2, demonstrating the decline in articles being published, and especially the lack of ERP-PIA publications in periods 2003 to 2005 (0), 2008 (o) and 2015-2016 (o). One would expect that as organisations spend large sums of money in adapting their ERP systems the reverse would be the case.

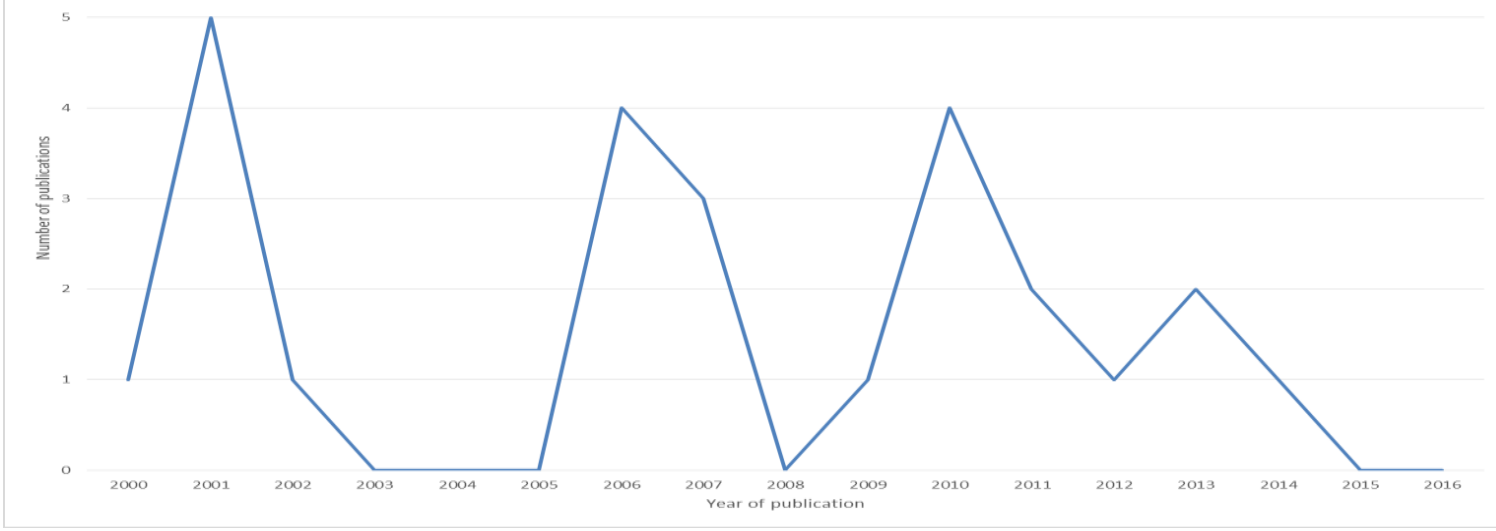

Figure 2. Number of ERP-PIA articles per year, 200O-2016

In the following section, we discuss Step 2, the research method for developing the framework and clarifying and analysing the ERP-PIA literature.

\subsection{Step 2 - ERP-PIA Framework}

The framework was developed based on a call for ERP post implementation research to focus on a lifecycle-wide view of ERP post-implementation activities (Gable, Chan, \& Tan, 2001). The importance of developing such a framework is its role in clarifying and providing an intensive view of particular aspects of the ERP-PIA literature (Webster \& Watson, 2002). This is presented in Figure 3 and consists of two sections: categories and phases of ERP- PIA.

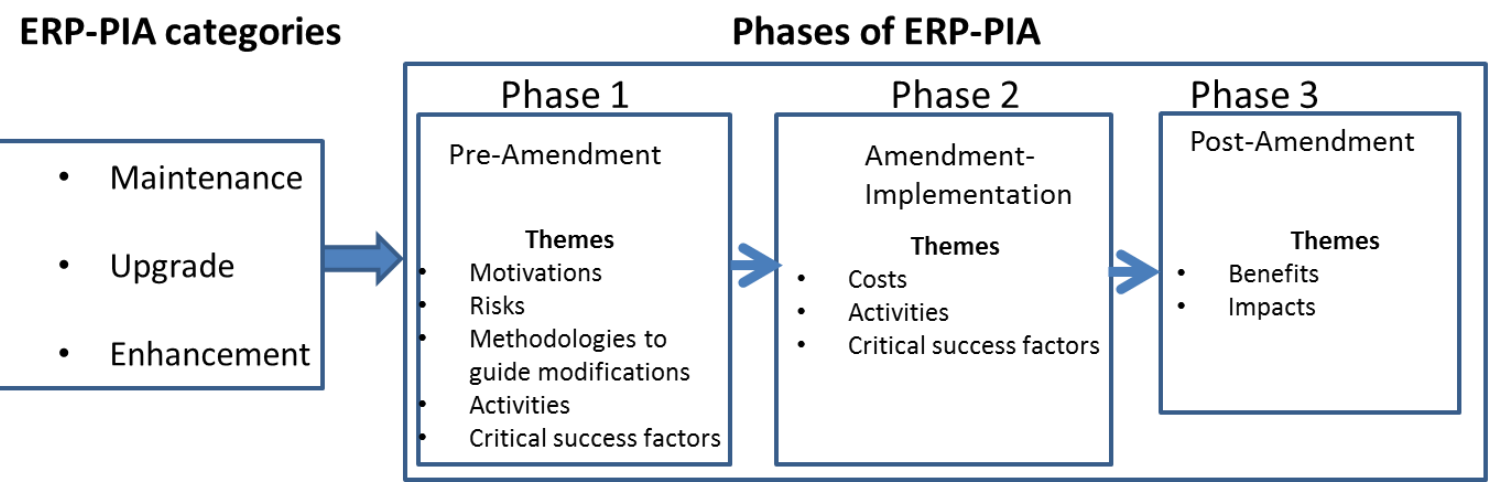

Figure 3. The ERP-PIA framework

This framework is valuable as it assists in the analysis of the ERP-PIA literature by: (a) providing a structure for the themes and key issues identified in the literature, (b) facilitating the classification of articles according to similarities and differences in categories and phases of ERP-PIA, (c) enabling a comparison of relative importance placed by various ERP scholars on different categories, phases, and themes of ERP-PIA, and (d) informing the identification of specific gaps within categories and phases of ERP-PIA.

This framework developed from the literature identifies three categories of amendments: maintenance, upgrades, and enhancement activities. As opposed to the available literature, we believe it is important to differentiate between upgrades, enhancements and maintenance as they produce varying effects on the ERP system and ultimately the organisation. These effects 
can be in terms of the benefits derived by the organisation by undertaking the amendment, or in terms of the effort that the organisation is required to invest in undertaking the amendment. An example of the former can be seen when organisations are undertaking enhancements and major upgrades. Such amendments are likely undertaken in response to post-implementation assessments and reviews (Cao, Nicolaou, \& Bhattacharya, 2010), with differences in the nature of the amendments impacting on the performance of the firm in relation to its use and enhancement of the ERP system (Nicolaou \& Bhattacharya, 2008). In other words, organisational effectiveness is often impacted by the decisions made regarding the extensions and continued use of ERP systems. An example of the latter can be seen in the level of effort an organisation needs to invest in an upgrade as opposed to implementing a support stack. For instance, undertaking a major upgrade is a non-trivial activity, often creating organisational challenges that were unexpected and can be prolonged (Khoo, Chua, \& Robey, 2011; Khoo, Robey, \& Rao, 2011).

Considering the fragmented nature of post-implementation studies, the framework is relevant and necessary for clarifying the scope of documented work relating to ERP postimplementation amendments. Using constructs (such as those included in the framework - the type and phases of amendments) is a pragmatic approach for deconstructing the existing literature and permits the identification of associations between constructs, if any exists. This is useful for identifying implicit aspects covered in the literature, especially because such associations are not always clearly mentioned in the literature.

\subsubsection{Three phases of ERP-PIA}

The ERP-PIA framework defines phases of amendments to include: Phase 1 - Pre-Amendment (before the amendment is undertaken); Phase 2 - Amendment-Implementation (while the amendment is conducted), and Phase 3 - Post-Amendment (after the amendment has been conducted).

In the development of our framework, key themes were extracted from the ERP-PIA literature based on the phase of amendment within which they were associated. Examples of such themes include: critical factors, motivation, activities costs and risks. In addition, these themes have been discussed with respect to the three different categories of amendments; for example, we discuss the influence of motivation on maintenance, enhancements as well as upgrades.

We now present (as shown in Table 2) a list of ERP-PIA articles identified in our literature search (Step 1), showing the categories of ERP-PIA [Maintenance (M), Upgrade (U), and Enhancement (E)], and the themes identified across the three phases. The table also indicates the theoretical perspectives and methodology utilised in the ERP-PIA articles. 


\begin{tabular}{|c|c|c|c|c|c|c|c|c|c|c|c|c|c|}
\hline \multirow{3}{*}{ Reference } & \multirow{3}{*}{$\begin{array}{l}\text { ERP-PIA } \\
\text { Category }\end{array}$} & \multicolumn{10}{|c|}{$\begin{array}{l}\text { Themes across ERP-PIA Phases } \\
\end{array}$} & \multirow{3}{*}{$\begin{array}{l}\text { Theoretical } \\
\text { perspective }\end{array}$} & \multirow{3}{*}{ Methodology } \\
\hline & & \multicolumn{5}{|c|}{ Pre-Amendment } & \multicolumn{3}{|c|}{ Amendment-Implementation } & \multicolumn{2}{|c|}{ Post-Amendment } & & \\
\hline & & $\begin{array}{l}\text { Motive for } \\
\text { PIA }\end{array}$ & $\begin{array}{l}\text { Risks in } \\
\text { PIA }\end{array}$ & $\begin{array}{l}\text { Method. } \\
\text { for PIA }\end{array}$ & $\begin{array}{l}\text { Activities } \\
\text { in PIA }\end{array}$ & $\begin{array}{l}\text { Critical Factors } \\
\text { for PIA }\end{array}$ & $\begin{array}{l}\text { Cost of } \\
\text { PIA }\end{array}$ & $\begin{array}{l}\text { Activities } \\
\text { in PIA }\end{array}$ & $\begin{array}{l}\text { fritical Pactors } \\
\text { for PIA }\end{array}$ & $\begin{array}{l}\text { Benefit } \\
\text { of PIA }\end{array}$ & $\begin{array}{l}\text { Impact } \\
\text { of PIA }\end{array}$ & & \\
\hline $\mathrm{Ng}$, Gable, and Chan (2002) & $\mathrm{M}, \mathrm{U}, \mathrm{E}$ & * & & & $*$ & & & * & & * & * & - & Case study \\
\hline Salmeron and Lopez (2012) & M & & * & * & & $*$ & & & $*$ & & & $\begin{array}{l}\text { Fuzzy Cognitive } \\
\text { Maps }\end{array}$ & Expert Panel \\
\hline Kwon and Lee (2001) & $\mathrm{M}$ & & & $*$ & & & & & & & & - & $\begin{array}{l}\text { Multi-Agent Intelligen } \\
\text { System }\end{array}$ \\
\hline Salmeron and Lopez (2010) & M & & & & & * & & & * & & & - & $\begin{array}{l}\text { Literature Review and } \\
\text { Expert Panel }\end{array}$ \\
\hline López and Salmeron (2014) & M & & * & * & & & & & & & & $\begin{array}{l}\text { Augmented Fuzzy } \\
\text { Cognitive Maps }\end{array}$ & Modelling \\
\hline Peng and Nunes (2009) & $\mathrm{M}$ & & * & & & & & & & & & - & Literature Review \\
\hline Hirt and Swanson (2001) & $\mathrm{M}, \mathrm{U}$ & & & & $*$ & & & $*$ & & & & - & Case Study \\
\hline Nah, Faja, and Cata (2001) & $\mathrm{M}, \mathrm{U}$ & & & & $*$ & & & $*$ & & & & - & Multiple Case Study \\
\hline Ng and Gable (2010) & $\mathrm{M}, \mathrm{U}$ & & & & * & & & & & & & - & Case Study \\
\hline Law et al. (2010) & $\mathrm{M}$ & & & & & $*$ & & & * & & & & Case Study \\
\hline Light (2001) & $\mathrm{M}$ & & & & & * & & * & * & & * & - & Case Study \\
\hline $\operatorname{Ng}(2001)$ & $\mathrm{M}, \mathrm{U}, \mathrm{E}$ & & & & & & * & & & * & & - & Case Study \\
\hline Fryling (2010) & $\mathrm{M}, \mathrm{U}, \mathrm{E}$ & & & & & & * & & & & & $\begin{array}{l}\text { Simulation } \\
\text { Modelling }\end{array}$ & Case Study \\
\hline Kremers and Dissel (2000) & $\mathrm{U}$ & * & & & & & & & & & & - & - \\
\hline $\begin{array}{l}\text { Min Khoo and Robey } \\
\text { (2007) }\end{array}$ & $\mathrm{U}$ & $*$ & & & & & & & & & * & - & Realist Case Study \\
\hline Khoo, Chua, et al. (2011) & $\mathrm{U}$ & * & & & & & & & & & & $\begin{array}{l}\text { Relational } \\
\text { Foundation Model }\end{array}$ & Case Study \\
\hline Khoo, Robey, et al. (2011) & $\mathrm{U}$ & & & & & & & & & & * & $\begin{array}{l}\text { Communication } \\
\text { Framing Theory }\end{array}$ & Inductive Case Study \\
\hline Zarotsky, Pliskin, and Heart & $\mathrm{U}$ & * & & & & & * & & & & & - & Case Study \\
\hline Dempsey, Vance, and & $\mathrm{U}$ & $*$ & & & & & & & & & & - & Case Study \\
\hline Peslak, Subramanian, and & $\mathrm{U}$ & & & & $*$ & & & $*$ & & & & - & Survey \\
\hline Beatty and Williams (2006) & $\mathrm{U}$ & & & & & $*$ & & & & & & - & - \\
\hline Nah and Delgado (2006) & $\mathrm{U}$ & & & & & * & & & $*$ & & & - & Multiple Case Study \\
\hline Olson and Zhao (2007) & $\mathrm{U}$ & & & & & $*$ & & & $*$ & & & - & - \\
\hline $\begin{array}{l}\text { Nicolaou and Bhattacharya } \\
(2006)\end{array}$ & $\mathrm{U}, \mathrm{E}$ & & & & & & & & & * & & - & Industry Survey \\
\hline Cao et al. (2013) & $\mathrm{U}, \mathrm{E}$ & & & & & & & & & $*$ & & Real Options & Industry Survey \\
\hline $\begin{array}{l}\text { Malihe, Nor Hidayati, } \\
\text { Davide, and Mohammad }\end{array}$ & $\mathrm{M}, \mathrm{U}, \mathrm{E}$ & & & & & & & & & & & - & $\begin{array}{l}\text { Content Analysis and } \\
\text { Interviews }\end{array}$ \\
\hline
\end{tabular}

\section{Table 2: Analysis of ERP-PIA literature}


In the next section, we present findings from our analysis of the ERP-PIA literature.

\subsection{Step 3 - Discussion of Findings}

This section discusses findings from the ERP-PIA literature. One of the major findings and what we consider a major failing in the literature was the inconsistent use of the ERP-post implementation terminology making it difficult to clarify the terms. Many authors for example (Law et al., 2010; Ng, Chan, \& Gable, 2001; Ng, Gable, \& Chan, 2003; Ng et al., 2002) who referred to enhancements as well as upgrades literally placed them under the umbrella term 'maintenance'. This is problematic as the literature referring to maintenance not only describes maintenance activities, but also includes elements that can be linked to upgrades and enhancements. The implication of this is that all amendments after implementation are sometimes seen as compulsory non-beneficial activities rather than as opportunities to uphold best business practices (Edberg \& Olfman, 2001).

As is the case with traditional in-house software literature, ERP maintenance has been defined to encompass all post-implementation activities undertaken from the time the ERP goes live through to its retirement (López \& Salmeron, 2011; Ng et al., 2002). One author even considered maintenance as a phase conducted during an implementation (Peslak et al., 2007). The concept of maintenance, in the traditional software maintenance literature as defined by the Institute for Electrical and Electronics Engineers (IEEE), encompasses "amendment of a software product after delivery to correct faults, to improve performance or other attributes, or to adapt the product to a modified environment" (IEEE, 1998). Many researchers define maintenance as: "the process of identifying and performing changes required for improving or maintaining system usability and performance throughout the ERP post-implementation stage" (López \& Salmeron, 2014; Nah et al., 2001; Ng et al., 2002). We argue that postimplementation amendments are generally classified as maintenance, and include the application of hot packs, import of new objects from ERP vendor, version upgrade amongst others. Some articles even document all kinds of post-implementation amendments (Ng, 2001; $\mathrm{Ng}$ et al., 2002), others simply focus on a single kind (Khoo \& Robey, 2007; Nah et al., 2001).

Consequently, we argue that dissimilar activities such as installation of upgrades, service packs and maintenance of custom codes, have been classified in some literature as maintenance (Khoo, Chua, et al., 2011), but should be called amendments and appropriately linked to maintenance, enhancements and/or upgrades for clarification purposes.

Following on from the review of the terminology, we now discuss the two major sections of our framework: categories and phases of ERP- PIA.

\subsubsection{Categories of Post-implementation Amendment}

The three ERP-PIA categories identified in the framework include maintenance, upgrade, and enhancement.

Maintenance: ERP maintenance refers to regular post-implementation activities required to keep the ERP system sustained. Our argument is that any effort carried out in maintaining an ERP system but which does not focus on improving or enhancing the system and which also is not a minor or major upgrade should be categorised as maintenance. Therefore, maintenance includes requests for support package or patches, on-going system and help desk support, as well as bug fixes and is typically directed at minor corrections and further adjustments due to legal changes (Ng, 2001; Ng et al., 2002; Worrell, 2007). Consequently, we suggest that general maintenance activities are not typically expected to have significant business and technical change impacts.

In the ERP maintenance literature, maintenance activities are classified into many categories, most of which are adapted from traditional software maintenance literatures. For instance, $\mathrm{Nah}$ et al. (2001) classifies ERP maintenance into six categories (Corrective, Adaptive, Perfective, Preventive, User support, and External Parties), three of which (Corrective, Adaptive, and Perfective) are defined by Swanson (1976). According to Swanson (1976), the purpose of Corrective maintenance is to correct faults; Adaptive maintenance to accommodate 
changes in the data and processing environments; and Perfective for performance improvement in form of Enhancive maintenance (which include changes and additions to system functionality) and Non-functional perfective maintenance. To accommodate ERP software in particular, Nah et al. (2001) also defined other dimensions such as preventive, user support and external parties.

Maintenance activities can also be divided into client-side and vendor-side maintenance $(\mathrm{Ng}$, 2001). Client-side maintenance focuses on maintenance requests initiated by the client and refers to bug-fixes and help-desk requests; whereas vendor-side maintenance includes the application of hot-packs (system patches), enhancement packs and online service system (OSS) notes that provide updates on patches for the system. It should be noted that the terminology varies by vendor for instance, SAP refers to enhancement packages and support pack stacks for initiating maintenance activities. However enhancement packs may also be used to fulfil functional requirements such as activating updates to business processes that are initiated by the vendor.

Upgrade: Upgrades are vendor-provided packages that contain substantial new features, and are weighted in terms of scope and version. (Nah et al. 2001; $\mathrm{Ng} 2001$ ). The scope of an upgrade describes the extent of implementation and is defined in technical or functional terms: technical upgrades keep the system in a supported version, while functional upgrades refer to new software functionality which can lead to business process improvement.

Panaya solutions (Technical-SAP-upgrade, n.d.) define a technical upgrade as "an upgrade undertaken to move the already implemented system onto the latest technology platform, without the implementation of new functionality that are able to change user behaviour or business processes". A technical upgrade is motivated by the need to maintain a technological infrastructure that is able to support required change and is usually not accompanied by any significant difference in the core product or functions (Technical-SAP-upgrade, n.d.). As such, technical upgrades are necessary in order to keep abreast with advancing technology (Chorafas, 2001), and are likely to be accompanied by a high technical impact but low business impact. A functional upgrade on the other hand is undertaken solely for the purpose of gaining substantial enhancements as well as new functionality (Fryling, 2010; Khoo, Robey, et al., 2011; Kremers \& Dissel, 2000; Ng, 2001). A functional upgrade is defined as "an upgrade undertaken to extend the business process functionality of an existing system (FunctionalSAP-upgrade, n.d.), and it is more complex than a technical upgrade and involves the adoption of new business processes as well as automation of previously un-automated processes". Also, functional upgrades are largely initiated as part of a line-of-business initiative unlike the technical upgrades which are usually initiated by the IT department. In fact, functional upgrades are usually expected to be preceded by technical upgrades and are expected to have both high business impact and high technical change impact (Ng, 2001).

Upgrade version on the other hand describes an upgrade in terms of whether it reflects a move within the same series or to a different series, and can be a minor or a major upgrade.

We consider an upgrade to be an improvement to the current software from an older version of the same software product. Implementing a completely new system (even if it is similar) is considered to be outside the scope of this construct.

Enhancement: Enhancements are undertaken to specifically increase the performance of the system by further adapting the system to meet organisational requirements ( $\mathrm{Ng} \mathrm{2001;} \mathrm{Ng}$ et al. 2002). We expect enhancements to bring about a high business impact.

Generally, enhancements encompasses maintenance activities targeted towards the improvement of software (Hirt \& Swanson, 2001). In the context of ERP systems, enhancements are considered to be add-ons and upgrades (Nicolaou \& Bhattacharya, 2006), and aim to provide additional business functionality to the system. Moreover, a maintenance request is considered to be an enhancement request based on the measure to which it contributes to business objectives (Gable et al., 2001). Enhancement efforts also include the design and implementation of customizations, as well as creation or amendment of user 
interfaces (Worrell, 2007). Considering the high business involvement in enhancement tasks, we consider that enhancement amendments should be treated and categorised differently to maintenance amendments. Enhancements are associated with improvements initiated both from the client-side and vendor-side. Some examples of client-side enhancements include configuration by setting parameters via the ERP interface, add-on packages, tables and text enhancement, creation of customer-specific objects such as screens and reports, workflow programming to create non-standard workflows, and interface development to interface the ERP system with various legacy systems ( $\mathrm{Ng}$ 2001; Nicolaou and Bhattacharya 2006). From the vendor driven side, enhancements may come in the form of hot-packs that initiate new functionality and capabilities. These packs are often developed for use in the current system and for which organisations may find more preferable to implement than outlaying the cost of a full-blown upgrade.

Having identified the three major categories of ERP post-implementation amendments, we now explain the three major phases of ERP post-implementation amendments.

\subsubsection{Phases of ERP post-implementation amendments}

The phases of ERP post-implementation amendments are identified as Phase 1 -PreAmendment, Phase 2 - Amendment, and Phase 3 - Post-Amendment. Within each phase, several themes are identified. These themes represent major issues identified from the literature which have been shown to influence post-implementation amendments. We now discuss the ERP-PIA categories with respect to the phases and themes. We note that this discussion is presented as identified in the ERP-PIA literature. For instance, we find that in some cases discussion of themes do not cut across all categories of amendments, and as such impose a gap. As an example, Nah and Delgado (2006) discuss critical success factors for upgrades without touching on maintenance and enhancement. On the other hand, Law et al. (2010) discusses CSFs for maintenance without discussing on upgrades and enhancements. Consequently enhancements are exempted from our discussion on the CSF theme as no literature was found discussing this.

\section{Phase 1 - Pre-Amendment}

In this phase, amendments are conceived and planned. Five themes are identified for this phase: motivations, risks, methodologies, activities, and critical success factors.

Phase 1 - Theme 1 (Motivation) - Motivation refers to high-level objectives of an organisation to initiate a particular project (Smith, Rahim, Shanks, \& Johnston, 2008). Motivation is discussed against the three ERP- PIA categories: maintenance, upgrades and enhancements.

Maintenance: motivations for conducting maintenance include requests for user-support, master-data-change, corrections, and patches (Ng et al., 2002). User-support requests address system functionalities and difficulties associated with human-computer interaction; change requests are aimed at corrections and fixing bugs; while master-data change requests deal with updates to the master data file. Patches are used to fix bugs in the existing system, adapt to external environmental changes such as government regulations, and maintain the installed system in its operational standard required by the vendor; thus ensuring the system meets the contractual arrangements of maintenance and support ( $\mathrm{Ng}, 2001$; $\mathrm{Ng}$ et al., 2002).

Upgrades: motivations for ERP upgrades can be classified based on the source of the upgrade (Khoo \& Robey, 2007; Khoo, Robey, et al., 2011), and the reason for the upgrade (Kremers \& Dissel, 2000; Ng et al., 2002). The motivation for ERP upgrades originates from both internal as well as external forces. Internal forces refer to internal requirements generated by the client organisation who has installed the ERP system; for example the need for more benefits. Other examples of internal motivating forces include the availability of resources to facilitate the upgrade, and the corporate and IT policies to mitigate software risks. External forces refer to the external dependence placed squarely on the ERP vendor; examples include the functionality of the software and the level of technical support provided by the vendor (Dempsey et al., 2013). Other motivating factors reflect business reasons, technical reasons and environmental reasons (Kremers \& Dissel, 2000). Business reasons reflect the need for 
added functionality such as that affecting a core method of carrying out a business activity. Technical reasons may include compliance with government standards, expiration of vendor support for an installed version, and keeping the system up-to-date (Dempsey et al., 2013; Zarotsky et al., 2006). Environmental reasons refer to pressure from the value chain, such as a business partner requiring a specific functionality in the system.

Enhancements: Enhancements are motivated by a business need and are requested to seek improvement and optimise business processes; for instance, adjusting a particular module of the ERP system to better suit the business needs of the organisation ( $\mathrm{Ng} 2001 ; \mathrm{Ng}$ et al. 2002).

Phase 1 - Theme 2 (Risks) - Risks can threaten the positive outcomes of amendment projects (Salmeron and Lopez 2012). Post-implementation ERP risks are defined as an event that has consequences or impacts the use, maintenance, and enhancement of implemented ERP systems (Peng \& Nunes, 2009). In the ERP-PIA literature, only risks specifically related to maintenance activities have been documented; risks pertaining to ERP upgrades and enhancement have not been reported. Prior to undertaking an amendment, risks may be caused by continuous changes in scope/objectives of amendments or conflicting requirements in the design of the amendment. These risks strongly affect ERP maintenance performance, specifically ERP user satisfaction. Thus, it is critical to control risks in the Pre-Amendment phase because risks, if not addressed early, can negatively influence the outcome in the PostAmendment phase. One recommended way to reduce risks is to develop risk strategies early in order to successfully identify and mitigate the risk (López \& Salmeron, 2011; Salmeron \& Lopez, 2012).

Phase 1: Theme 3 (Methodology to guide Amendments) - 'Methodology' as a theme in the ERPPIA literature concerns the approaches that facilitate and support amendments. The ERP-PIA literature only focuses on methodologies for ERP maintenance, excluding methodologies for upgrades and enhancements. Only two methodologies were identified from the literature: problem solving algorithms by Kwon and Lee (2001) and Fuzzy Cognitive Maps by Salmeron and Lopez (2012). These are discussed here.

(i) To ensure the highest level of operation of the ERP system in the organisation, Kwon and Lee (2001) suggest that the ERP system must be combined with problem solving algorithms if effective ERP system maintenance is to be achieved in the Amendment phase. They propose a multi-agent intelligent system architecture to alleviate ERP maintenance efforts. In addition, they propose that in the Pre-Amendment phase, plans are defined to establish for continuity and autonomy.

(ii) Salmeron and Lopez (2012) propose a framework, referred to as the Fuzzy Cognitive Map (FCM), for managing the process of undertaking ERP maintenance. Arguments for the framework follows that ERP maintenance is ambiguous and that there are no clear frameworks to define how best ERP professionals should manage the maintenance process. This framework is designed to address the need for a systematic methodology to predict the effects of risks on the maintenance and simulated distinct scenarios depicting how risks may affect the maintenance being undertaken.

Phase 1 - Theme 4 (Activities in Pre-Amendment) - Activities related to Pre-Amendment have been identified by ERP scholars in attempt to differentiate ERP amendments from custombuilt IT software amendments. Although activities are often referred to as characteristics in the literature we argue that activities effectively characterise ERP-PIA (Nah et al., 2001). Hirt and Swanson (2001); Nah et al. (2001); Peslak et al. (2007) identify activities peculiar to maintenance and upgrade type amendments only; activities in enhancement type amendment are not identified. Firstly we will discuss maintenance activities, followed by upgrade activities.

Maintenance Amendment: ERP maintenance activities occurring in the Pre-Amendment phase are described by Ng and Gable (2010) as maintenance preparation. Specific activities in maintenance preparation include: (i) defining maintenance, (ii) estimating maintenance resources, (iii) managing relationship with the vendor, and (iv), defining all maintenance management issues. These activities are designed to aid the maintenance procedure by 
outlining maintenance objective, the maintainer's roles and responsibilities, resources required, and maintenance strategies.

Upgrade Amendment: Activities in Pre-Amendment where upgrades are involved focus on the justification and planning of new software versions (Nah et al. 2001). Such activities include: the design of a project methodology for the upgrade, researching upgrade options, developing a business case, and performing impact analysis between a new version and a previously installed version.

Phase 1 - Theme 5 (Critical success factors) - Critical success factors (CSF) are areas of influence that, if not addressed and managed at the Pre-Amendment phase, can impact on Post-Amendment activities. Several studies identified critical success factors in ERP upgrade activities, while one study addressed critical factors for ERP maintenance. CSFs will be discussed against maintenance and upgrade categories only as we found no studies reporting CSFs for enhancement amendments.

Maintenance: Law et al. (2010) developed a framework of critical success factors (CSF) for ERP maintenance and support and identified some very valuable CSFs. A major observation in this framework is that the CSFs proposed are not unique to ERP maintenance, but can be extrapolated to a full blown ERP implementation as well. They identified, critical factors contributing to effective performance of ERP maintenance and support activities to include: (i) the implementation strategy - a poorly defined implementation approach not only leads to implementation issues but also makes maintenance and support difficult; (ii) the formulation of clear organisation structures and clearly defined roles and responsibilities contribute to the effective operation and execution of maintenance activities; (iii), client-vendor alignment maintaining a strategy that aligns with the vendor's services and product strategies; (iv) the ability to leverage ERP expertise from multiple sources; (v) ensuring a level of support and participation by stakeholders; and (vi) communication and co-ordination among functional units at all levels of personnel.

Upgrade: For upgrade projects to be successfully achieved Beatty and Williams (2006) recommend companies build their business case on new functionality, treat the upgrade project as a new business project, and utilise the initial implementation project team, a practice not easily achieved. Organisations are advised to integrate these factors into their upgrade plans to deliver quality systems on time and within budget. Likewise, Nah and Delgado (2006) found that the factors critical to a successful upgrade project include having a business plan and vision, determining the type and amount of organisation change necessary to accommodate the upgrade, defining and evaluating the project scope to avoid scope creep, and planning for effective communication between project team members and stakeholders.

\section{Phase 2 - Amendment-Implementation}

The Amendment-Implementation phase is described as the period where an amendment is in the process of being implemented. Three major themes pertaining to implementing an amendment include cost, activities, and critical success factors. Each theme is discussed:

Phase 2 -Theme 1 (Costs) - Costs as a theme in the Amendment-Implementation phase pertains to factors that influence the cost of implementing an amendment. This theme will be discussed against the ERP-PIA categories: maintenance, upgrades and enhancement.

Maintenance: The costs associated with ERP maintenance are greatly impacted by the manner in which the application of patches are managed ( $\mathrm{Ng}$ 2001). For example, maintenance costs are determined by the estimated number of hours and cost of labour to implement the patch. Additionally, the number of changes included as part of the maintenance is known to impact maintenance costs (Fryling, 2010; Ng, 2001). For instance, it may be necessary to revisit all customisations when applying new updates.

Upgrade: Costs associated with an upgrade could be minimal or large scale, and are usually dependent on such costs as software license fees, support and maintenance costs, hardware, user-training, consultancy fees, and previous enhancement amendment re-application costs 
(Ng 2001). When an upgrade is within the same series (e.g from $3.1 \mathrm{H}$ to $3.1 \mathrm{I}$ ), it is much cheaper than upgrading to a higher software series (e.g from $3.1 \mathrm{H}$ to $4.6 \mathrm{~B}$ ). This is because an upgrade within the same series excludes licensing costs and maintenance and support costs, not to mention training and general organisational change approaches, and very often is freely provided. An upgrade to a higher series on the other hand is accompanied by numerous changes in system structure, business processes and possibly the architecture (Fryling 2010; $\mathrm{Ng}$ 2001). While testing associated with an upgrade also introduces cost as the help of external testing firms may be required (Zarotsky et al., 2006).

Enhancement: Enhancement costs usually comprise the labour cost multiplied by the numbers of hours per enhancement. If the enhancement requires users to be trained, then the cost of end user training must also be included ( $\mathrm{Ng} 2001)$.

\section{Phase 2 - Theme 2 (Activities involved in implementing an amendment)}

Maintenance: Activities involved in the implementation of maintenance amendments are described as maintenance procedure ( $\mathrm{Ng}$ \& Gable, 2010). These activities include the monitoring of patch introduction; receipt and classification of maintenance request, request for vendor support, problem analysis and solution design, and finally the application of vendor patch.

Upgrade: Activities occurring in the implementation phase of an upgrade include: the installation and construction of new version in a DEV system (the testing environment); conduct testing and trial upgrades between the DEV system and quality assurance system (QAS); and ultimately the conversion (or go live) in the PRD (production system) (Ng and Gable 2010).

Enhancement: Enhancement activities are aimed at obtaining benefits from the ERP system, and are designed to improve business processes ( $\mathrm{Ng}$ et al. 2002). As such, activities that characterise the implementation of enhancements include development of new reports as well as new features in reports, generating new interface, creating new program or software functionality, improving existing program functionality, and updating business processes.

Phase 2 - Theme 3 (Critical success factors) - In this phase critical factors such as project management, change management, and effective communication between project team and stakeholders are identified ( $\mathrm{Nah}$ and Delgado 2006). These factors are however no different from those identified in the pre-implementation phase.

\section{Phase 3-Post-Amendment}

Major themes in the literature concerning the post implementation phase of an amendment mainly refer to the impact of the changes from the amendment. These themes include: business benefits and impacts.

Phase 3 - Theme 1 (Business benefits) - The ERP-PIA literature refers to benefits as business performance improvements after undergoing amendments. Some of these benefits are related to new and improved functionality, increased accurate sales planning or forecasting relative to competitive advantage, better availability of information for managers to support globalisation, and reduction in the number of third-party legacy systems ( $\mathrm{Ng} \mathrm{2001;} \mathrm{Ng}$ et al. 2002). Unlike maintenance activities which usually do not contribute to any business benefit, benefits to organisation performance are most often obtained from upgrades and enhancements, especially when the upgrades and enhancements are performed within the first few years of implementing a new ERP version (Cao et al. 2013; Nicolaou and Bhattacharya 2006). Although post-implementation changes generally affect a firm's performance; the timing of the changes also has a marked impact on performance improvements. For instance, ERP-adopting firms that initiate enhancements in the form of either add-ons or upgrades soon after the implementation, tend to enjoy superior differential performance benefits when compared to their non-ERP peers (Cao et al. 2013; Nicolaou and Bhattacharya 2006).

Phase 3 - Theme 2 (Impact of the Amendment) - ERP-PIA are expected to impact both the ERP system itself as well as the benefits obtainable from the system (Galy \& Sauceda, 2014). 
The ERP-PIA literature documents some impacts resulting from amendments, especially with respect to ERP upgrades. For instance, impacts from upgrades are explained in terms of the effect of the upgrade on the existing system, IS staff, and key users of the system (Khoo et al. 2011b; Ng et al. 2002). However impacts from maintenance and enhancement activities are not documented.

Upgrade: ERP upgrades are known to impact on the installed ERP system, as well as on IS staff. The impact of an ERP upgrade on the existing ERP system can be measured in terms of three relationships: relationship between the vendor and the systems, relationship on and between IT support staff and vendors, and the relationship among systems (Khoo and Robey 2007). The impact of the upgrade on support staff is evidenced in the relationship between the IS staff and end users in supporting and training users after upgrades have been implemented. As a result of changes in user interfaces due to an upgrade, the relationship among users is impacted as users find a need to increase their interaction to assist each other during upgrades.

The above subsections have discussed the ERP-PIA framework and identified the major themes from the literature. A number of gaps in the literature were observed that could serve as future directions for ERP research. These directions are discussed in the following section.

\section{Future Research Directions and Recommendations}

In this section, we discuss the research gaps. This discussion is presented in accordance with the ERP-PIA framework in three steps: first, the gaps are presented in Figure 4, and are discussed as future research directions (RD); second, we reflect upon how these directions could extend the existing literature; third, suggestions identifying how these directions can be empirically examined are presented.

\section{Phases of ERP-PIA}

\begin{tabular}{|c|c|c|}
\hline Phase 1 & Phase 2 & Phase 3 \\
\hline $\begin{array}{l}\text { Pre-Amendment Gaps } \\
\text { Influence of organisational type and size } \\
\text { on motivations for PIAs is unknown } \\
\text { Need for methodology and guidelines } \\
\text { for prioritising PIAs } \\
\text { Lack of studies documenting critical } \\
\text { factors to be considered before initiating } \\
\text { PIAs }\end{array}$ & $\begin{array}{l}\text { Amendment-Implementation Gaps } \\
\text { Lack of information on organisational } \\
\text { learning occurring during implementation } \\
\text { of PIAs } \\
\text { No documentation on how PIAs are } \\
\text { associated with business process changes } \\
\text { No reports of user training occurring } \\
\text { during the implementation of PIAs } \\
\text { Critical success factors for successful } \\
\text { implementation of PIAs are unknown }\end{array}$ & $\begin{array}{l}\text { Post-Amendment Gaps } \\
\text { - Lack of information on how } \\
\text { organisations measure benefits } \\
\text { resulting from PIAs }\end{array}$ \\
\hline
\end{tabular}

Figure 4. Gaps identified in the ERP-PIA literature

\subsection{Phase 1 (Pre-Amendment) Research Directions}

RD1: The influence of organisation type and size on motivations for amendments - The studies addressing motivations for amendments primarily involve single case studies. To extrapolate the findings of single case studies, we recommend multiple case studies of different organisation types and sizes to enable comparisons across several organisations and provide a broader picture of the influence of differences in organisational motivations for amendments.

RD2: Principles for prioritising amendments - To better understand how organisations prioritise amendments, it may be useful to investigate possible criteria that could be of value for choosing a particular amendment over another. For instance, it may be more cost effective to perform a particular kind of amendment at a particular point in time. It may however also be the case that a more extensive amendment may be capable of preventing further amendments. A study to understand what criteria underlie the amendment choices that organisations make would be an appropriate approach. 
RD3: Critical factors for initiating amendments - Some contingency factors inhibiting or influencing the timing of amendments are suggested in the literature. For instance, the availability of resources is known to be a factor that determines whether or not upgrades are undertaken or delayed (Khoo and Robey 2007). However, there may be other factors that need consideration before a particular amendment is undertaken. As an example, the level of expertise of the organisation to effectively utilise the amendment may be an important factor. To investigate critical factors influencing how amendments are initiated, semi-structured surveys could be chosen, identifying several examples of amendments and asking what factors would ideally be considered by the management of an organisation before such amendments are undertaken.

\subsection{Phase 2 (Amendment-Implementation) Research Directions}

RD4: Organisational learning during Amendment-Implementation - Activities involved in amendments have been documented in the literature ( $\mathrm{Ng}$ and Gable 2010). It may be interesting to find out whether amendments actually demonstrate an organisation's learning approach. For instance, an organisation could choose a particular learning style for one amendment and adopt another learning style for another amendment. Hence, a variation in learning styles across several amendment instances may be observed. In a similar fashion, a variation in learning styles for similar amendments could be investigated across several organisations. In a case, where organisation A and organisation B undertake a similar kind of amendment, do both organisations adopt the same or different learning approaches? The influence of organisational learning is important because different organisational learning approaches are found to produce different outcomes (Hunter, 2003). In particular, Kraemmerand, Møller, and Boer (2003) suggest that post-implementation; activities reflect different learning approaches and in turn influence firm performance differently. Further arguments follow that the use and maintenance of existing capabilities suggest exploitation, whereas the search for alternate capability suggests exploration (Kraemmerand et al., 2003; Tomblin, 2010). Based on the different features that characterise each learning type, it can be argued that post-implementation amendments to ERP systems can be classified using these learning concepts. Such a classification is significant because amendments can be indicative of learning and at the same time hamper learning. For example, given the inherent tension between exploitation and exploration, the tendency to explore versus exploit is affected by several factors such as resources, organisational culture, and structure and as such a focus on exploitation can inhibit exploration (Otieno, 2010). Organisations' behaviours may also be a relevant lens for studying amendments and may facilitate a better and complete framework in the future.

RD5: Business process changes during amendments - Noting that an organisation faces options about the types of amendments to undertake, an important investigation to make during amendment endeavours concerns organisations' willingness or openness to accommodate changes to business processes. Davenport et al. (2004) argue that an organisations' configuration and implementation of ERP systems should be accompanied by business process re-engineering, coupled with changes in managerial processes to exploit the new data. However, existing research shows that due to the amount of time and resources necessary for a successful implementation, business process changes during ERP implementation in organisations are usually only minimal, if undertaken at all. Therefore, business process changes occurring during post-implementation become the focus of value derived from the implemented systems. In fact, existing research demonstrates that significant value can only be achieved if organisations continue to optimise business and management processes (Harris \& Davenport, 2006). It would be valuable to know why some organisations are open to making business process changes during one amendment and not doing the same for another.

RD6: User training during Amendment-Implementation - Training accompanying initial ERP implementation project is one of the critical success factors identified in the literature and is recognised as one of the factors that does not end after the project has been concluded (Nah 
and Delgado 2006). In fact, training is recommended to continue as organisations make further changes to their systems, and is considered as one of the key factors to successful ERP maintenance, and upgrades (Law et al. 2010). Understanding how organisations manage the training process during the Amendment-Implementation phase thus appears necessary. For example, if business process changes are made alongside the amendment, then is there a need for training to accompany such amendment to facilitate a smooth transition to new business practices? If continuous changes are made to the ERP system, do organisations have a process to cater for user training needs? Is it possible that the level of user training required for a particular amendment is a factor that determines how the amendment is undertaken and how much business process changes are introduced during the Amendment-Implementation?

RD7: Critical success factors during Amendment-Implementation - One of the observations from our literature analysis is that the ERP literature documents several critical success factors for ERP implementation but is very limited with regards to the post-implementation phase. The post-implementation CSFs are however inherited from the ERP implementation literature, and as such there is a need to investigate CSFs that are specific to the postimplementation phase.

\subsection{Phase 3 (Post ERP-PIA implementation) Research Directions}

RD8: Capturing the outcomes of amendments - Post-implementation audit and reviews are recommended after ERP implementations to assist organisations in capturing whether or not the benefits anticipated from implementation endeavours have been realised. It appears logical to reason that similar efforts be undertaken after amendments have been made to the ERP system. A limited number of studies have been conducted to measure the impact of such amendments following initial implementations (Nicolaou \& Bhattacharya, 2008; Nicolaou, 2004). These studies have however been conducted using secondary data. While this is valuable for indicating performance outcomes from amendments, the impact of amendments may not always reflect on the overall organisational performance. As such, first-hand operational effects of amendments also need to be captured. Do organisations investigate and measure operational benefits from amendment initiatives. If yes how are these measured? From these questions, researchers could propose methodologies that are able to assist organisations with such efforts providing support to the Amendment-Implementation phase.

RD9: Factors influencing the outcomes of amendments - Several factors may influence outcomes of amendment efforts. Such factors may include motivation, learning, and training. For instance, do motivating forces for undertaking ERP-PIAs contribute to the benefits derived from the amendment? Does the organisational learning approach adopted for an amendment influence its benefits? Or could training be one of the factors that influence what benefits are derived? An understanding of the factors that influence outcomes of amendments may indicate a relationship amongst different types of amendments and outcomes that organisations may experience.

\section{Conclusion and Limitations}

ERP post-implementation amendments are of practical importance as is the case with initial ERP implementations. However, the attention given to ERP-PIA in the academic and practitioner literature appears to be relatively small compared to that of initial implementations. This is considered to be a major failing as organisations continually need to decide on how to manage and maintain the systems after implementation. Understanding ERP-PIA is therefore an important subject to be included in academic and practitioner literature, especially since future benefits, obtainable from ERP systems, are moderated by post-implementation changes.

This paper has documented a review of the literature concerning ERP post-implementation amendments in order to clarify terminologies and to present an overview of the current state of research in the field of ERP-PIA. While only a small number of articles discuss ERP-PIA, our review identified three categories and three phases of ERP-PIA. In addition, relevant 
themes such as costs, critical success factors, and motivation, amongst others were covered in the ERP-PIA literature. However, other themes like training and organisational learning have been identified as missing, but relevant to ERP-PIA.

Furthermore, with a goal to assist the formulation of a research agenda for future ERP research, this paper presents a contribution to the ERP literature by developing a framework to analyse ERP-PIAs. The framework provided a logical sequence for the discussion of predominant amendment themes and aided the development of further research directions. Practical implications of this paper concern the importance of ERP-PIA. ERP managers must understand differences in ERP-PIAs as well as possible outcomes, if effective outcomes are to be achieved. The framework is useful for exposing where managerial efforts and resources should be directed to foster successful uptake of ERP-PIA, thereby facilitating better decisions regarding how and when amendments should be undertaken.

ERP systems have been of interest over the last two decades and the number of publications has increased enormously over the last 10-17 years. However, the topic of post-implementation amendments is still developing. It is our recommendation that scholars pay attention to ERPPIA as the era of new ERP implementations is over and amendments are essential for the realisation of further benefits.

The review presented in this paper is not without limitations. Like other literature reviews, the paper is largely dependent on selected keywords and publication outlets. To eliminate such limiting factors, the review process for published articles covering post-implementation amendments was carefully conducted; first beginning with articles in the AHCPIS list and then expanding the search to include other relevant journal outlets.

\section{References}

ACPHIS. (2013). IS journal ranking. Retrieved from http://www.acphis.org.au/index.php/isjournal-ranking

Beatty, R. C., \& Williams, C. D. (2006). Erp ii: Best practices for successfully implementing an erp upgrade. Communications of the ACM, 49(3), 105-109.

Cao, J., Nicolaou, A. I., \& Bhattacharya, S. (2010, June 28, 2010.). A longitudinal study of market and firm-level factors influencing ERP systems adoption and postimplementation system enhancement options. Paper presented at the 7 th International Conference on Enterprise Systems, Accounting, and Logistics (ICESAL), Rhodes, Greece.

Cao, J., Nicolaou, A. I., \& Bhattacharya, S. (2013). A longitudinal examination of enterprise resource planning system post-implementation enhancements. Journal of Information Systems, 27(1), 13-39.

CFO Research Services. (2009). The high cost of change for erp: What does it cost to keep up to date? . Retrieved from http://www.cfo.com/whitepapers/index.cfm/displaywhitepaper/13316056

Chorafas, D. N. (2001). Integrating ERP, CRM, supply chain management, and smart materials. Boca Raton: Auerbach Publications.

Davenport, T. H., Harris, J. G., \& Cantrell, S. (2004). Enterprise systems and ongoing process change. Business Process Management Journal, 10(1), 16 - 26.

Dempsey, S., Vance, R., \& Sheehan, L. (2013). Justification of an upgrade of an enterprise resource planning (ERP) system - the accountant's role. Global Journal of Human Social Science, 13(1).

Edberg, D., \& Olfman, L. (2001, 3-6 Jan. 2001). Organizational learning through the process of enhancing information systems. Paper presented at the System Sciences, 2001. Proceedings of the 34th Annual Hawaii International Conference on Information Systems. 
Fryling, M. (2010). Estimating the impact of enterprise resource planning project management decisions on post-implementation maintenance costs: A case study using simulation modelling. Enterprise Information Systems, 4(4), 391-421.

Functional-SAP-upgrade. (n.d.). Retrieved from http://www.panayainc.com/articles/thecase-for-the-functional-sap-upgrade.html

Gable, G. G., Chan, T., \& Tan, W.-G. (2001). Large packaged application software maintenance: A research framework. Journal of Software Maintenance and Evolution: Research and Practice, 13(6), 351-371.

Galy, E., \& Sauceda, M. J. (2014). Post-implementation practices of erp systems and their relationship to financial performance. Information \& Management, 51(3), 310-319.

Gartner. (2003). IT spending: How do you stack up? Retrieved from http://www.gartner.com/research/attributes/attr_47450_115.pdf

Harris, J. G., \& Davenport, T. H. (2006). New growth from enterprise systems: Achieving high performance through distinctive capabilities. Retrieved from

Hirt, S. G., \& Swanson, E. B. (2001). Emergent maintenance of erp: New roles and relationships. Journal of Software Maintenance and Evolution: Research and Practice, $13(6), 373-387$.

Hunter, S. D. (2003). Information technology, organizational learning, and the market value of the firm. JOURNAL OF INFORMATION TECHNOLOGY THEORY AND APPLICATION, 5(1), 1-28.

IEEE. (1998). IEEE standard for software maintenance, IEEE Std 1219-1998. (pp. 47). New York: Institute of Electrical and Electronic Engineers.

Information Resources Management Association. (2011). Enterprise information systems: Concepts, methodologies, tools and applications

Khoo, H. M., Chua, C. E. H., \& Robey, D. (2011). How organizations motivate users to participate in support upgrades of customized packaged software. Information \& Management, 48(8), 328-335.

Khoo, H. M., \& Robey, D. (2007). Deciding to upgrade packaged software: A comparative case study of motives, contingencies and dependencies. European Journal of Information Systems, 16(5), 555-567.

Khoo, H. M., Robey, D., \& Rao, S. V. (2011). An exploratory study of the impacts of upgrading packaged software: A stakeholder perspective. Journal of Information Technology, 26(3), 153-169.

Klans, H., Rosemann, M., \& Gable, G. G. (2000). What is ERP? Information System Frontiers, 2(2), 141-162.

Kraemmerand, P., Møller, C., \& Boer, H. (2003). ERP implementation: An integrated process of radical change and continuous learning. Production Planning \& Control, 14(4), 338348.

Kremers, M., \& Dissel, H. V. (2000). ERP system migration: A provider's versus customer's perspective. Communications of the ACM, 43(4).

Kwon, O. B., \& Lee, J. J. (2001). A multi-agent intelligent system for efficient ERP maintenance. Expert Systems with Applications, 21(4), 191-202.

Law, C. C. H., Chen, C. C., \& Wu, B. J. P. (2010). Managing the full ERP life-cycle: Considerations of maintenance and support requirements and it governance practice as integral elements of the formula for successful ERP adoption. Computers in Industry, 61(3), 297-308. 
Light, B. (2001). The maintenance implications of the customization of ERP software. Journal of Software Maintenance and Evolution: Research and Practice, 13(6), 415-429.

López, C., \& Salmeron, J. (2011). Exploring risk factors in ERP maintenance projects. Scientific Journal of Riga Technical University. Computer Sciences, 43(-1), 50-56.

López, C., \& Salmeron, J. L. (2014). Modeling maintenance projects risk effects on erp performance. Computer Standards \& Interfaces, 36(3), 545-553.

Malihe, M., Nor Hidayati, Z., Davide, A., \& Mohammad Akbarpour, S. (2015). Developing instruments for enterprise resources planning (ERP) post-implementation failure model. International Journal of Enterprise Information Systems (IJEIS), 11(3), 68-83.

Min Khoo, H., \& Robey, D. (2007). Deciding to upgrade packaged software: A comparative case study of motives, contingencies and dependencies. European Journal of Information Systems, 16(5), 555-567.

Motiwalla, L. F., \& Thompson, J. (2009). Enterprise systems for management. New Jersey: Pearson Education.

Nah, F. F.-H., \& Delgado, S. (2006). Critical success factors for enterprise resource planning implementation and upgrade. The Journal of Computer Information Systems, 46(5), 99-113.

Nah, F. F.-H., Faja, S., \& Cata, T. (2001). Characteristics of ERP software maintenance: A multiple case study. Journal of Software Maintenance and Evolution: Research and Practice, 13(6), 399-414.

Nash, K. S. (2007). ERP: How and why you need to manage it differently. Retrieved from http://www.cio.com/article/2421027/enterprise-software/erp--how-and-why-youneed-to-manage-it-differently.html

Ng, C. S.-p., \& Gable, G. G. (2010). Maintaining ERP packaged software - a revelatory case study. Journal of Information Technology, 25(1), 65-90.

$\mathrm{Ng}$, C. S. P. (2001). A decision framework for enterprise resource planning maintenance and upgrade: A client perspective. Journal of Software Maintenance and Evolution: Research and Practice, 13(6), 431-468.

Ng, C. S. P., Chan, T., \& Gable, G. G. (2001, 2001). A client-benefits oriented taxonomy of erp maintenance. Paper presented at the IEEE International Conference on Software Maintenance (ICSM 2001), 7-9 November 2001. .

Ng, C. S. P., Gable, G., \& Chan, T. (2003). A revelatory case study into the adequacy of standard maintenance models in an ERP context. Paper presented at the 7 th Pacific Asia Conference on Information Systems, 10-13 July 2003, , Adelaide, South Australia.

Ng, C. S. P., Gable, G. G., \& Chan, T. (2002). An ERP -client benefit-oriented maintenance taxonomy. Journal of Systems and Software, 64(2), 87-109.

Nicolaou, A., \& Bhattacharya, S. (2008). Sustainability of ERPs performance outcomes: The role of post-implementation review quality. International Journal of Accounting Information Systems, 9(1), 43-60.

Nicolaou, A. I. (2004). Quality of postimplementation review for enterprise resource planning systems. International Journal of Accounting Information Systems, 5(1), 25-49.

Nicolaou, A. I., \& Bhattacharya, S. (2006). Organizational performance effects of ERP systems usage: The impact of post-implementation changes. International Journal of Accounting Information Systems, 7(1), 18-35.

Olsaker, E. (2010). An unlikely place to find cost savings: ERP software maintenance and support annual fees. Government Finance Review. Retrieved from 
http://www.gfoa.org/unlikely-place-find-cost-savings-erp-software-maintenance-andsupport-annual-fees

Olson, D. L., \& Zhao, F. (2007). CIOs' perspectives of critical success factors in erp upgrade projects. Enterprise Information Systems, 1(1), 129-138.

Otieno, J. O. (2010). Enterprise resource planning systems implementation and upgrade: (a Kenyan study). (Doctor of Philosophy), Middlesex University.

Peng, G. C., \& Nunes, M. B. (2009). Surfacing ERP exploitation risks through a risk ontology. Industrial Management \& Data Systems, 109(7), 926-942.

Peng, G. C., \& Nunes, M. B. (2010). Why ERP post-implementation fails? Lessons learned from a failure case in china. Paper presented at the 14th Pacific Asia Conference on Information Systems, Taipei, Taiwan.

Peslak, A. R., Subramanian, G. H., \& Clayton, G. E. (2007). The phases of ERP software implementation and maintenance: A model for predicting preferred ERP use. Journal of Computer Information Systems, 48(2), 25-33.

Salmeron, J. L., \& Lopez, C. (2010). A multicriteria approach for risks assessment in ERP maintenance. Journal of Systems and Software, 83(10), 1941-1953.

Salmeron, J. L., \& Lopez, C. (2012). Forecasting risk impact on erp maintenance with augmented fuzzy cognitive maps. Software Engineering, IEEE Transactions on, 38(2), 439-452.

Smith, S. P., Rahim, M. M., Shanks, G., \& Johnston, R. B. (2008). How organization goals affect interorganization system implementation projects: Evidence and implications. Asia Pacific Management Review, 13(3), 567-581.

Swanson, E. B. (1976). The dimensions of maintenance. Paper presented at the Proceedings of the 2nd international conference on Software engineering, San Francisco, California, United States.

Technical-SAP-upgrade. (n.d.). Retrieved from http://www.panayainc.com/articles/thecase-for-the-technical-sap-upgrade-keeping-up-with-business-and-technologyevolution.html

Tomblin, M. S. (2010). Theory development in enterprise systems and organizational learning. Journal of Organizational Computing and Electronic Commerce, 2O(4), 398-416.

Webster, J., \& Watson, R. T. (2002). Analyzing the past to prepare for the future: Writing a literature review. MIS Quarterly, 26(2).

Worrell, J. L. (2007). Running the ERP marathon: Enhancing ERP - business fit in the postimplementation phase. Florida state university.

Zarotsky, M., Pliskin, N., \& Heart, T. (2006). The first ERP upgrade project at DSW: Lessons learned from disillusion with simplicity expectations. Journal of Cases on Information Technology, 8(4), 13-23.

Copyright: (C) 2017 Oseni, Foster, Maburbhir, Smith. This is an open-access article distributed under the terms of the Creative Commons Attribution-NonCommercial 3.0 Australia License, which permits non-commercial use, distribution, and reproduction in any medium, provided the original author and AJIS are credited. 


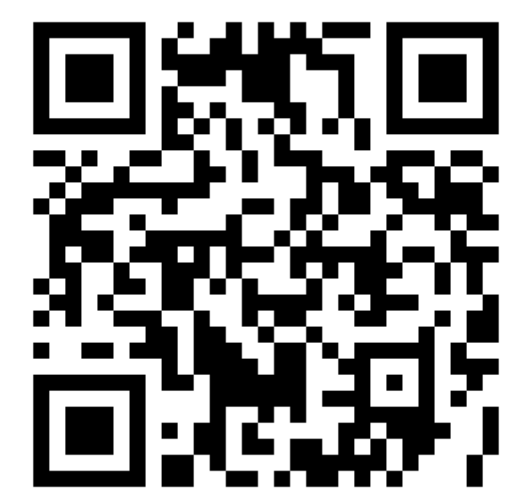

